\title{
Safety \& Environmental Risk Management: Borrowing from the Past to Enhance Knowledge for The Future
}

\author{
Evangelia Fragouli ${ }^{1}, \&$ Faye Nzioka ${ }^{2}$ \& Selma Manar ${ }^{2}$ \\ ${ }^{1}$ School of Business, University of Dundee, Dundee, UK \\ ${ }^{2}$ CEPMLP, University of Dundee, Dundee, UK \\ Correspondence: Evangelia Fragouli, School of Business, University of Dundee, Dundee., DD1 4HN, UK. Tel: \\ 44-013-8238-5772. E-mail: e.fragouli@dundee.ac.uk
}

Received: November 22, 2019 Accepted: December 14, 2019 Online Published: December 30, 2019

\begin{abstract}
The oil and gas industry is facing more and more challenges in the latest decades. Indeed, as oil and gas became more difficult to be found, new areas are targeted, as deep water offshore or more hostile environments like Alaska. These involve high technology industry and imply deep uncertainty. Thus, the application of classical approaches of risk management is limited, as shown by major safety and environmental oil disasters like the Deep Water Horizon Accident. This paper analyses the later as a case study, to discuss the complexity of safety and environmental risk management in deep-water drilling. Given this complexity, the paper will also analyse how feedback from previous accidents can improve knowledge, and change the perception and thus the way safety and environmental risks are managed in deep-water drilling. The findings of the paper contribute to development of risk management policy and risk decision making.
\end{abstract}

Keywords: safety risk, environmental risk, deep water horizon, deep-water drilling, feedback from crisis

\section{Introduction}

In high technology industries, risk management become more complex. Indeed, in these high cost industries, managers are required to make the best risk/efficiency tradeoff (Voort, 2009) in one hand, and manage unknown uncertainties in the other hand. This is especially the case for deep-water offshore drilling in the oil and gas industry, where the level of uncertainty is even greater, especially when it comes to safety and environmental risks (Skogdalen, 2011). The complexity and uncertainty under which offshore drilling operations are conducted are clearly shown by the numerous environmental disasters that occurred over time, in spite of the risk management programs implemented by Oil and Gas companies. Thus, classical risk management framework can reveal itself to be inappropriate in such conditions (Park, 2011). This paper aims to examine how uncertainties that safety and environmental risk management faces in deep-water offshore drilling can be reduced through feedback from previous disasters. A case study of the Deep Water Horizon blow-out in the offshore of the golf of Macondo will lead to some conclusions regarding the impact of a crisis on the perception and then the management of safety and environmental risk in this area. Indeed, a crisis or a disaster is an indicator that the initial risk/efficiency tradeoff made by managers was not adequate, and can provide new information and data to help achieve a better understanding of the risk level (Skogdalen, 2011) and prevent such events from happening. The first section of this paper examines the complexity of environmental and safety risks management in the deep-water drilling and to what extent the high reliability theory is relevant in this context, especially in the case of the deep water horizon accident. The second section will then discuss the improvement of environmental and safety risk management through feedback from previous accidents, analyzing the evolution of the perception of risk when more knowledge is acquired, the improvement of safety indicators and discussing the concept of adaptive risk management

\section{Environmental and Safety Risks}

\subsection{Overview of the Deep-water Drilling}

Before the falling of oil prices that the petroleum industry is facing from 2014, offshore drilling for oil and gas has expanded significantly, targeting increasingly hostile environments (Boesch, 2012). When the promises of finding important quantities of hydrocarbons have been proven by the past discoveries and the development of geological and geophysical studies, operating in such areas comes with tremendous technological challenges (National Research Council, 2016). These challenges are raised by the ultra-deep water depth, the high pressure and high 
temperature conditions of hydrocarbon reservoirs, the depth of the targeted reservoir and the hostility of the geological formations (Shlumberger, 2014).

Each step and each section of these operations involve different risks, from market risk, financial risk, geological risk, technological risk, political risk... But also, safety and environmental risks linked to the so feared "blowout" that can occur while operating in such conditions. A blowout is the consequence of a loss of control of the well. This happens due to an uncontrolled flow of fluids (oil, gas or saline water) to the surface. It is a powerful explosion as the pressure of the fluid is very high, and it usually results in destruction of the platform, death of the present personnel and huge environmental damage (API, 2010; Skogdalen, 2011). Moreover, these kinds of events also involve reputation risk. (Fragouli, 2015). Indeed, the consequences of a blowout or an environmental disaster in general gives a bad image of the company causing a devaluation of its shares and long episodes of law suits and investigations. Therefore, oil and gas companies operating in hostile environment have every interest in considering safety and environment as a first priority and make every necessary study to take the most appropriate decision for environmental and safety risks management.

\subsection{Environmental and Safety Risks Management in the Deep-Water Drilling}

There is no doubt that risk management and especially environmental and safety risk management in this domain is not without complexity (Aven, 2007). Indeed, deep water drilling involves high technology that can be categorised as high risk technology regarding the catastrophic consequences of a system failure and the repeated disasters that happened in the past (Heiman, 2005). Moreover, the regulations and policies regarding environment and safety in offshore drilling operations are usually overlapping and conflicting, which adds more difficulties for managers to seek compliance with environment and safety standards in their risk management program (Ornelas et al., 2014). Also, disasters in offshore drilling were found linked to geological uncertainties, especially in complex environment like deep offshore where the lack of geological knowledge is very common (Shaughnessy et al., 2003). Finally, the reality of business requires most of the time from managers to make risk efficiency tradeoffs, usually with limited knowledge about the real risk (Voort, 2009). Therefore, regarding all these aspects, safety and environmental risk management in deep offshore drilling involves numerous challenges and uncertainties. In this section, we are going to develop each of the above aspects to examine in which way they challenge a classical risk management framework.

\subsubsection{High Risk Technologies}

Scholars of the high reliability theory claim that failure is not a fatality when dealing with high risk technologies, and that successful risk management can be achieved with certainty when dealing with risky technologies. Four principles according to this movement, govern effective risk management in high risk technologies. These are explained in more details by Heiman (2005):

- $\quad$ The high priority given to safety by political leaders (Roberts, 1991; LaPorte and Consolini, 1991);

- The design of organisations and processes with back up options (Bendor, 1985);

- The delegation of power to lower levels of authority in order to foster the appropriate response in case of an incident (Weick, 1987);

- And finally the development of a learning system from previous incidents encountered (Morone and Woodhouse, 1986; Woodhouse, 1988).

From another perspective, organisational reliability has been criticised after discussion and analysis by Heiman (1997) and Heiman (2005) who state that hazards related to high risk technologies cannot be fully controlled. Indeed, according to the GPO Heiman (2005) criticise the high reliability theory in its lack of providing elements for the durability of successful risk management of high risk technologies. Thus, high reliability theorists provide a basis for a proper safety risk management in high risk technologies but cannot ensure a complete control over the uncertainties these involve and those are the first drivers behind repeated failures. It therefore gives material direction through which improvement can be achieved over time, as long as knowledge evolves by learning from precedent mistakes.

\subsubsection{Conflicting Regulations}

Regulations and standards are determinant in the outcomes of safety risk management in offshore drilling as far as evacuation and alarm procedures are concerned (Skogdalen, 2012). More generally, the regulatory system and connection between regulating bodies plays and important role in preventing major safety and environmental accident in offshore drilling (Skogdalen, 2011). However, these regulations are usually found to be overlapping and conflicting due to their plurality, causing confusion to operators in offshore drilling (Ornelas, 2014). Moreover, 
two deficiencies according to regulations of offshore drilling activities are pointed out by Ornelas (2014) in his study regarding the "overlapping powers and competencies on offshore drilling and production activities". First of all, the focus of the laws is more oriented toward supervision rather than frequent and targeted inspection for accident prevention. And second, he warns about the opportunities for operators to escape penalties for environmental and safety irregularities due to conflicting regulations. This is to say that environmental and safety risk management in the oil and gas industry, and especially in the very risky and complex environment of offshore drilling, goes beyond efforts and risk management willing of oil and gas companies. It must be supported by a strong and coherent regulatory system co-created by Government and operators to address the main issues related to safety and environment of offshore drilling activities.

\subsubsection{Lack of Geological Knowledge}

Risk management in deep offshore drilling is also related to geology. This is especially reservoir and formation properties, that even if studied deeply involve a high degree of uncertainty (Abimbola, 2014). The undesired disasters arising from geological hazards are usually prevented in the oil and gas drilling activities by two principal safety barriers: The drilling mud and the Blow Out Preventer Stacks (BOP). The drilling mud usually has to exercise a pressure that is between the formation pressure and the drilling margin (Skogdalen, 2012). This means that it should control the pressure without damaging the reservoir to the point it will become uncommercial. The second safety barrier, the BOP, is "an assembly of specialized valves or similar mechanical devices installed, during drilling, between the wellhead system and the drill floor. It is used to seal, control and monitor the well in case of blowout" (IFP School). However, in deep and ultra-deep offshore conditions, formations and reservoirs are characterized by high pressures, high temperatures, and lower drilling margin. These properties complicate processes of drilling and well control, as the higher the formation's pressure is, the bigger the risk to damage the reservoir while trying to control the pressure (Shaughnessy, 2003). Therefore, the design of drilling tools and blow out preventers as well as calculations of the optimal drilling fluid density are highly challenged in deep offshore activities by deep the geological uncertainty that characterize the latter.

\subsubsection{Risk/Efficiency Trade-Off}

How far a company is willing to invest in order to address an uncertainty depends on the manager's perception of this hazard. Although a detailed risk assessment is realised and its results presented to the board of directors, the final decision belongs to the top management, who decides or not to allocate the necessary funds to mitigate a risk with high consequences but low probability. These are the trade-offs between risk and efficiency that managers are required to make, to ensure what they imagine to be financially the best for the company (Teece, 2009). Therefore, the selection process of risk is to bias the risk management process, because it is made on a subjective basis (Douglas, 1982). Moreover, the perception of the risk is built on a limited knowledge about the real danger that is to be faced. Indeed, deep water drilling reveals itself to be a 'highly complex environment'. Therefore, according to Voort (2009) knowledge about the real risk is limited and always involves deep uncertainty. Therefore, the optimum balance between risk management's cost and efficiency is not an absolute value. Numerous scenarios and alternatives are available, and when the decision needs to be made with confidence, no guarantee is given about the certainty of the latter.

\subsection{Safety and Environmental Risk management failures: Case of Deep Water Horizon Disaster}

In order to illustrate the complexity of safety and environmental risk management in deep offshore drilling, this paper examines the Deep-water horizon disaster as a case study. We do not aim to describe what happened, rather, this section will determine different organisational failures and mistakes in risk management that led to this event. This case has been chosen because it gives a complete image of a hostile drilling environment, where complexity and lack of knowledge combined with weaknesses in the risk management process led to a catastrophic failure.

The Deep-Water Horizon disaster occurred on the evening of the $10^{\text {th }}$ of April 2010. The British Petroleum offshore drilling rig in the gulf of Macondo was about to end drilling the well (Graham, 2011), when a powerful blowout happened after a loss of control of the well causing the explosion and fire on the rig. After this disaster, eleven members of the crew were killed and seventeen injured (BP, 2010). It was the worst environmental disaster in the history of United States of America causing huge human, economic and environmental damage (Skogdalen, 2011; USDI, 2010).

\subsubsection{Deep Water Horizon and High Reliability Theory}

According to the GPO oil commission report, this accident showed the need for a more engaged commitment to safety and environment in the United States energy policy in order to conduct offshore drilling in a safe manner (Graham, 2011). Moreover, the design of the well was chosen to be the cheapest, with a lack of redundancy of 
safety barriers, appropriate to the high pressure expected from the reservoir (Hammer, 2010). Also, investigation reports findings show that the risk culture in British Petroleum (BP) was one that encourage productivity with less considerations of safety (Graham, 2011). Finally, the learning curve for safety and environmental risk management appears to barely move in BP, as the company encountered previous disasters with similar causes, but failed to take into consideration the recommendation that resulted from investigations (DHSG, 2011). Therefore, as far as the high reliability theory is concerned, safety and environmental risk management of the deep-water horizon did not follow appropriately the four principles for a successful risk management.

However, managers were confident about the level of safety under which operations were conducted before the accident (Graham, 2011). Indeed, good will is shown by the conduct of the negative pressure test to ensure the BOP's and the well's integrity, few hours before the blowout. However, the results of this pressure test were misinterpreted, which failed to prevent a disaster from happening (Hammer, 2010). This underlines one of the weaknesses of the theory, where error is not taken into consideration as Heiman suggests. Thus, the Deep-Water Horizon disaster illustrates how not considering the probability of errors compromise the durability of a successful safety and environmental risk management in high risk technologies. Error appears to be one of the key element for a sustained risk management. Thus, it is paramount to reduce its probability in managing risk with high risk technologies. This is primarily possible by gaining knowledge through experience and learning from precedent failures.

The blowout of the Macondo well is also related to the complexity of the geology in the Gulf of Mexico. Indeed, this region is characterized by unique geological properties compared to gulfs all over the world (Skogdalen, 2011). Although millions of dollars were initially spent in order to understand the geology and the particularities of the Gulf of Mexico, and among them the drilling of the Macondo well (Graham, 2011), no one successfully interpreted the geological data to predict the incapability of the well and rig design to prevent a blowout. Thus, this case study shows that when it comes to geology in poorly explored environments, geological knowledge and awareness is gained throughout the conduct of operations and it should be completed by lessons and findings learnt after such disasters (Hammer, 2010).

As usual in any business, risk management and especially those risks not obviously related to the financial health of the company, i.e. safety and environmental risks, involve a financial study to examine to what extent it is financially acceptable to invest in managing those risks. This is particularly true in the case of the Macondo well, as clearly stated in the DHSG final report: "analysis of the available evidence indicates that when given the opportunity to save time and money - and make money - trade-offs were made for a certain thing -production because they were perceived to be no downsides associated with the uncertain thing - failure caused by the lack of sufficient protection. Thus, because of a cascade of deeply flawed failure and signal analysis, decision-making, communication, and organizational - managerial processes, safety was compromised to the point that the blowout occurred with catastrophic effects." (DHSG, 2011). Therefore, a crisis can reveal that the initial trade-off was not appropriate, as the company's financial performance decrease significantly after a safety or environmental disaster.

Overall, the high reliability theory can be applied to each aspect of safety and environmental risk management in deep water drilling. From managing high risk technologies, geology, regulatory systems to making risk efficiency trade-offs. However, the need for confidence under the complexity and the deep uncertainty of the situation led to an unreal perception of the risk and even sometimes to unintentionally ignore the hazard. This is the main cause behind the percentage of error present and inherent in the classical risk management approach, and that is one of the principal limitations of this approach when applied to highly complex environments with deep uncertainty.

\section{Improving Environmental and Safety Risk Management in Deep-Water Offshore Drilling through Dynamic Risk Management}

It has been proven that deep water drilling is a complex context for risk management and especially for safety and environmental risk management. It is to mention that although this paper discusses these two types of risks, implications can be done concerning other risk, particularly reputation and financial risk. Indeed these four types of risk are closely related to each other in petroleum projects. Any environmental and safety disaster will dramatically affect the firm's reputation, and therefore have important implication on its share values and other financial indicators. Thus, oil and gas companies have every interest in improving the way to manage environmental and safety risks in their petroleum projects. In deep-water drilling, the uncertainty involved dictates that knowledge is the key element of an improved understanding of risk and thus a better management of the latter (Xie, 2010). The main purpose is to reduce the percentage of error that is eminent to traditional risk management approaches, and to take into consideration the rapid change of the distribution of risk in such complex industries (Kalantarnia, 2009). Therefore, an appropriate approach toward environmental and safety risk management in 
deep-water drilling would be a dynamic approach (Khan, 2016), that continuously process knowledge to update the distribution of the risk, and thus, be the closest possible to the assessment of the real risk.

\subsection{Dynamic Risk Management}

Dynamic risk management is defined by Khan, 2016 as a "method that updates estimated risk of a deteriorating process according to the performance of the control system, safety barriers, inspection and maintenance activities, the human factor, and procedures". Knowledge appears to be the corn stone behind that continuously updating process. The objective is to obtain the best informed decision-making as far as risk-efficiency tradeoffs are concerned. Indeed, A crisis or a failure usually reveal that the initial tradeoff was not appropriate, as the company's financial performance decrease significantly after a safety or environmental disaster. In this context, different approaches have been developed regarding the way such knowledge is acquired., knowledge can depend on:

-The feedback from historical accident and disasters (Voort, 2009)

-The risk culture in the company (Khan, 2016)

-The perception of the risk (Douglas, 1982)

\subsection{Learning from Disasters for a Better Risk and Safety Management}

A "major accident" in the offshore oil and gas industry is often stated to be, for example by HSE (2010), "an accident out of control with the potential to cause five or more fatalities, caused by failure of one or more of the system's safety and preparedness barriers".

Skogdalen et.al (2011) stated that the Deepwater Horizon accident was a consequence of breakdowns on numerous aspects in the handling of safety. These levels are described by Rasmussen (2007) as:

1. work and technological system

2. staff level

3. management level

4. company level

5. regulators and associations level

6. government level

The BP investigation report (2010) of the Macondon well blow out establishes a requirement to create "leading and lagging indicators for well integrity, well control and rig safety critical equipment, to include but not to be limited to, dispensations from drilling and well operations' practice, loss of containment, and overdue scheduled critical maintenance on BOP systems". Basically the report suggest that the equipment on the facility should be well maintained and up to date to avoid future accidents that may occur due to insufficient maintenance.

However, according to the American Petroleum Institute (API 2010) placing and using safety indicators is not as easy as one might think and depends on whether they are:

1. Capable of promoting process safety as well as and learning.

2. Simple enough for a proper understanding by different stakeholders with any interest in the company or organization.

\section{Exponentially effective at different levels}

4. Suitable for comparison with other firms and similar projects.

Thus, having a specific risk assessment is vital in predicting and mitigating any likely accidents from happening, particularly during the early planning phase.

The petroleum industry makes uses of various risk mitigation methods in the hopes of reducing any operational mishaps that may arise. These approaches have the objective of mitigating any potential failures or problems that may halt operations within the organization. (Grantham 2014).

The Swedish Radiation Safety Authority states that, "an organization has good potential for safety when it has developed a safety culture that shows a willingness and an ability to understand risks and manage activities so that safety is considered". Skogdalen and Tveiten (2010) define a safety climate simply as "the employees' perceptions, attitudes and beliefs about risk and safety"

Accidents causes can be cathegorised in 3 main clusters (Flin, 1994):

(1) Individual characteristics which refers to the worker's experience, knowledge and attitudes towards safety. 
(2) Job characteristics that is to say the type of work employees are carrying out and what it entails as well; and

(3) Platform characteristics which simply refers to the proper safety tools, systems and programs in the organization.

Furthermore, this study showed that the administrative commitment demonstrated in different aspects within the organization such as safety, job satisfaction and attitudes towards safety as opposed to production and job situation was more effective in regards to how workers' perceived risks and the level of satisfaction they had with the safety measures implemented.

In another study done by Alexander et.al. (1994) it was found that the safety values and principles within an operating company was termed through worker' attitudes and perceptions, by six factors, namely;

- Willingness of managers to manage the risk,

- Need to be reassured regarding personal safety,

- Quantification of the hazard,

- Punishment and personal responsibility for risk,

- Disagreements and misunderstandings with supervisors and

- $\quad$ Support and encouragement (Cox and Cheyne 2000).

In regards to the Deepwater Horizon accident one might questioningly observe whether the accident was in relation to system safety issues within the Deepwater drilling industry or a consequence of a single company working independently of the standards set by the industry generally (Vinnem 2011). A response to this suggestion would be difficult to obtain as various aspects would need to be considered. Observations would need to be analyzed and evaluated in the oil and gas industry over time in regards to preparedness and responses to big incidents or accidents in the industry. Indeed, Sylves (1998) observes that, "how damaging an oil spill is depends in part on the degree of emergency preparedness in place before the event, the speed of response, and the effectiveness of recovery operations once a spill has occurred". Therefore, it is of great importance for firms to develop dynamic capabilities that help achieve agility and ensure a rapid and dynamic respons to crisis (Teece, 2016). Because such events are not intentional, they are the product of an eminent deep uncertainty, feedbacks from investigations and event analysis are of great importance (Kjellén, 2000), as far as knowledge improvement is concerned. They provide new information about previous hidden deficiencies in the initial safety and environmental risk framework, and therefore contribute to adjust the later and avoid future disasters from happening.

\subsection{Risk Culture}

An effective update and process of knowledge in high-risk technologies projects, like deep-water drilling comes also with the day to day activities, routines and process. This means that it is directly related to all the personnel contributing in the systemique and interrelated ongoing of the project. Therefore, the awareness of these workers is crucial to an effective dynamic management. (Khan, 2016). Indeed, being directly in contact with the operational and technical aspects of the project, they can provide valuable information regarding changes and deviations of risk that they observe during their work. For example, in the case of deep water drilling, being aware of the safety culture of the company, workers will inform systematically in case of an abnormal behavior of the pressure, or if they observe indicators of leaks in the well integrity.

Creating a safety culture is changing attitudes and actions warranting that safety deviations will be regarded as of high importance. (Booth, 1996; ASCNI, 1993). An organization with a solid safety culture would push employees to ask questions when something is unclear or "doesn't seem right" and also encourage them to be demanding and have a careful manner in which they handle all areas of their jobs and create important better communication between workers on the ground and their superiors in higher management positions (Meshkati 1999).

The United States Bureau of Safety and Environmental Enforcement (2013) sets out the core traits of an effective safety culture in their safety culture policy statement as follows;

- Leadership: safety is incorporated into the leaderships values and actions. Leaders show their commitment to safety through their behavior and how they make their decisions with regards to safety.

- Personal accountability: everyone in the organization take responsibility for all areas related to safety whether is personal or process safety.

- Identification of problems and solutions: any issues or problems that may arise in relation to safety are promptly identified, analyzed, evaluated and addressed as quickly as possible. 
- Work processes: A system is set up for planning and controlling work activities to ensure safety is a priority. This also ensures that the correct equipment is used for the correct work as well.

- $\quad$ Continuous learning: employees are given chances to learn new ways to tackle safety and implement it. They are given continuous opportunity to learn about new procedures and methods of addressing safety and environmental issues that may arise.

- Safe Atmosphere for raising concerns: employees are able to feel free to raise any concerns or questions with regard to safety and environmental concerns, without any unease in regards to repercussions, reprisal, coercion, harassment, or discrimination.

- Effective safety communication: safety issues are easily communicated to employees and managers, therefore allowing for information to be passed down effectively.

- $\quad$ Respectful work environment: Trust and respect is felt throughout the organization.

- Questioning attitude: employees are not complacent, they develop a questioning attitude whereby they are free to ask questions if something does not "sit right" with them, for example employees can question managers and contractors can question employees if they feel something is out of bounds.

These nine traits are of extreme importance as they reflect all the areas within an organization that will need to be addressed in order for an effective safety culture to exist, for example a questioning attitude with employees actually encourages openness in an organization which will then reveal to the management if any issues need to be addressed and thus help in avoiding any safety problems on the offshore facility.

\subsection{Risk Perception and Offshore Drilling}

Perception is important because it demonstrates the manner in which risks are perceived within an organization. Perception is described by Hucynski and Buchanan (1991) as "the active psychological process in which stimuli are selected and organized into meaningful patterns". Furthermore, risk perception is important because, in the organizational sense, it is the way people i.e. managers, perceive risks, that is the manner in which they will be portrayed to their subordinates i.e. the employees. There have been several studies in relation to risk perception; Marek et al. (1985) in their study regarding the perception of risk and its relationship to accidents in deep water platformswho (Cox and Cheyne 2000), found out that the main outcomes in relation to safety and being able to carry out a safety policy, is proper safety management and activities that encourage safety, and including personnel's opinions when designing or rather creating safety programs.

Likewise, Rundmo (1993) executed a survey through questionnaires used on employees working in eight offshore platforms in the North Sea, Norway; with the aim of firstly, determining the employees thoughts in regards to factors of risk and, and to detect variances in the way they perceive risk among the assorted work groups. These studies showed employees who were the closest to the risk had the most disguised vision of the risk they face, and had the greatest willingness and appetite toward risk related to their activities. (Cox and Cheyne 2000). This goes to demonstrate that in the absence of an accident, individuals ignore the real perception of risks in relation to their work and therefore become more prone to accidents and injuries. Failures in safety risk management, or in other words safety accident and disasters are a reminder of the hazard and the danger involved in high technology industries.

Moreover, perception of the risk is a key element that accompain an adaptive risk management approach. "adaptive risk management is based on the acknowledgement that one best decision cannot be made, but rather, a set of alternatives should be enthusiastically tracked to gain information and knowledge about the effects of different courses of action.", according to Bjerga and Aven (2015)

Some of the problems that organizations are facing today are processes and activities within a company that are categorized by deep uncertainty. For example, examining and handling difficult "financial derivatives, novel technology, preparations for climate change", especially regarding the petroleum industry. In order to deal with the problem of deep uncertainty, vigorous and adaptive risk management programs are often suggested (Aven 2015).

When applying the above definition to the oil and gas industry we have found that this method is of great relevance to the oil and gas industry because the oil and gas industry is very unpredictable and thus applying an adaptive risk management scheme will really help a cooperation in preparing for uncertain circumstances as they will have already set up a scenario for each problem or risk that may arise thus leaving no room for any mistakes and the company will be able to tackle the problem head on as the scenarios will have already been discussed and prepared for. 
Adaptive risk management, which is mostly attributed to Holling (1978) is a procedure used when decision makers i.e. management find themselves in a situation of uncertainty, and is found to be made up of six main elements which are:

- Management's aims that are frequently reestablished.

- A pattern of the scheme being handled.

- A variety of management selections.

- Monitoring and evaluation of results.

- A instrument(s) for integrating knowledge into future decisions.

- A combined structure for stakeholders' involvement and learning (Bjerga and Aven 2015)

The elementary process is candid: that is to say that, when handling any system, a form of administrative action is chosen, its effects are monitored and altered based on the results (Linkov 2006)

Therefore, by implementing an adaptive risk management program in an organization allows management as well as employees to be prepared for different scenarios relating to problems or issues that may arise. Therefore, enabling them to address most of the issues or problems promptly as they have already been able to go over the situations prior to their occurrence. Adaptive risk management is a very important tool to have especially on and offshore facility as it really helps with preparedness and safety. However, adaptive risk management can bring confusion regarding which solution is the best adapted to the situation. Here, risk perception is key aspect of a risk management framework to have in an organization as it boils down to how everyone person in the organization is able to understand the risks that are faced within the company. This is especially true when it comes to managers. They are the final decision makers who decide on the final risk-efficiency trade-off they are willing to make. The point here is that an informed manager is crucial, but as complete as possible the information they get, their perception of the risk is the final psychological trigger behind the final decision. Indeed, the deep uncertainty in high risk technologies and particularly in deep water drilling cannot be fully controlled. New parameters and challenge are always discovered. (Teece, 2016). Managers usually have different alternatives for decision making, that all seems convincing in some point, as explained by the adaptive risk management approach. However, the dramatic consequences of major disasters provide a feedback in order to adjust the initial decisions, and contribute in changing manager's perception of the risk toward a closest perception to the real hidden risk their company faces in deep-water drilling projects.

\section{Conclusion}

This paper critically discusses the environmental and safety risks faced by offshore drilling oil and gas companies looking at the case study of the disastrous Deepwater Horizon blowout also Known as the Macondo Blowout of 2010. It highlights the complexity and the deep uncertainty involved in such project. This comes mainly from the high risk technology used in deep-water drilling, the lack of geological knowledge in newly explored areas, the conflicting aspect of environment and safety regulations, and the risk- efficiency tradeoffs that have to be made by managers. The high reliability theory provides for a classical management of each of these aspects, but given the uncertainty and complexity they involve, a high percentage of error compromise its effectiveness. Rather, this paper suggests that a combination of different approaches of dynamic risk management is followed for environmental and safety risk management in deep water drilling. Indeed, by comparing the different studies carried out by different researchers as regards how the incident could have been avoided and safety and environmental risks management improved, the following conclusions have been drawn:

- Previous accidents and disasters provide lessons and enhanced knowledge about risk. Thus feedback from such events is crucial for safety and risk environmental risk management improvements.

- It is important for an organization to incorporate a safety culture so as to be prepared for accidents and further problems.

- Previous accidents and disasters contribute in changing the perception of the risk toward a closest to the real risk perception, especially among managers that are the final decision makers.

\section{References}

Abimbola, M., Khan, F., \& Khakzad, N. (2014). Dynamic safety risk analysis of offshore drilling. Journal of Loss Prevention in the Process Industries, 30, 74-85. https://doi.org/10.1016/j.jlp.2014.05.002

ACSNI. (1993). Organising for Safety-Third Report of the Human Factors Study Group of ACSNI. HMSO, London. 
Adaptive Environmental Assessment and Management. In: Holling CS, editor. Chichester, UK: Wiley; 1978.

Alexander, M., Cox, S., \& Cheyne, A. (1994). The concept of safety culture within a UK based organization.

AlKazimi, M. A., \& Katiem G. (2015). Investigating New Risk Reduction and Mitigation In The Oil And Gas Industry. Journal of Loss Prevention in the Process Industries, 34, 196-208. https://doi.org/10.1016/j.jlp.2015.02.003

Ansell, J., \& Wharton, F. (1992). Risk. 1st ed. Chichester: Wiley.

API (American Petroleum Institute). (2002). Recommended Practice for Training and Qualification of Personnel in Well Control Equipment and Techniques for Wireline Operations on Offshore Locations, Recommended practice T-6 (1st ed).

API (American Petroleum Institute). (2006). Recommended Practice for Well Control Operations, Recommended Practise 59 (2nd ed).

API (American Petroleum Institute). (2007a). Contractor Safety Management for Oil and Gas Drilling and Production Operations, Recommended Practise 76 (2nd ed).

API (American Petroleum Institute). (2007b). Recommended Practice for Analysis, Design, Installation, and Testing of Basic Surface Safety Systems for Offshore Production Platforms, Recommended Practice 14C.

API (American Petroleum Institute). (2010). Isolating Potential Flow Zones During Well Construction, Recommended practice 65 - Part 2 (1st ed).

Aven, T., \& Heide, B. (2009). Reliability and validity of risk analysis. Reliability Engineering \& System Safety, 94(11), 1862-1868. https://doi.org/10.1016/j.ress.2009.06.003

Aven, T., Vinnem, J. E., \& Wiencke, H. S. (2007). A Decision Framework for Risk Management, With Application to The Offshore Oil and Gas Industry. Reliability Engineering \& System Safety, 92(4), 433-448. https://doi.org/10.1016/j.ress.2005.12.009

Baker, J., Bowman, F., Erwin, G., Gorton, S., Hendershot, D., \& Leveson, N. (2007). The Report of the BP US Refineries Independent Safety Review Panel.

Bendor, J. B. (1985). Parallel Systems: Redundancy in Government. University of California Press, Berkeley, CA.

Bjerga, T., \& Terje, A. (2015). Adaptive Risk Management Using New Risk Perspectives - An Example from The Oil and Gas Industry". Reliability Engineering \& System Safety, 134 ,75-82. https://doi.org/10.1016/j.ress.2014.10.013

Boesch, D. (2012). Deep-water drilling remains a risky business. Nature, 484(7394), 289. https://doi.org/10.1038/484289a

Booth, R. T. (1996). The promotion and measurement of a positive safety culture. In Stanton, N. (Ed.), Human Factors in Nuclear Safety (pp. 313-332). Taylor and Francis, London. https://doi.org/10.1201/9780203481974.ch15

BP. (2010). Deepwater Horizon Accident Investigation Report.

Cox LAT (2012). Confronting deep uncertainties in risk analysis. Risk Anal., 32, 1607-29. https://doi.org/10.1111/j.1539-6924.2012.01792.x

Cox, S. J., \& Cheyne, A. J. T. (2000). Assessing safety culture in offshore environments. Safety Science, 34(1-3), 111-129. https://doi.org/10.1016/S0925-7535(00)00009-6

DHSG (Deepwater Horizon Study Group). (2011). The Macondo Blowout, Final Report.

Douglas, M., \& Wildavsky, A. (1982). How can we know the risks we face? Why risk selection is a social process. Risk Analysis, 49-51. https://doi.org/10.1111/j.1539-6924.1982.tb01365.x

Engaged in offshore hydrocarbon processing. Proceedings of the Fourth Annual Conference on Safety and Wellbeing at Work, Loughborough University of Technology, UK, November 1-2.

Flin, R. H., \& Mearns, K. J. (1994). Risk Perception and Safety in the Offshore Oil Industry. Second International Conference on Health, Safety, and the Environment in Oil and Gas Exploration, Jakarta. https://doi.org/10.2118/27259-MS

Flin, R., Mearns, K., Fleming, M., \& Gordon, R. (1996). Risk Perception and Safety in the Offshore Oil and Gas Industry, (Offshore Technology Report OTH 94 454). HSE Books, Sudbury. https://doi.org/10.2118/35907MS 
Fragouli, E. (2015). Reputation Risk Management in the Petroleum Industry: The Role of Corporate Social Responsibility. The Hellenic Open Business Administration Journal, 1(2), 81-99.

Graham, B., Reilly, W. K., Beinecke, F., Boesch, D. F., Garcia, T. D., Murray, C. A., \& Ulmer, F. (2011). Deep water: The Gulf oil disaster and the future of offshore drilling (report to the President). National Commission on the BP Deepwater Horizon Oil Spill and Offshore Drilling.

Hammer, D. (2010). Five key human errors, colossal mechanical failure led to fatal Gulf oil rig blowout. The Times-Picayune.

Heimann, C. F. L. (1997). Acceptable Risks: Politics, Policy and Risky Technologies. University of Michigan Press, Ann Arbor, MI. https://doi.org/10.3998/mpub.14948

Heimann, L. (2005). Repeated Failures in the Management of High Risk Technologies. European Management Journal, 23(1), 105-117. https://doi.org/10.1016/j.emj.2004.12.015

Holmes, A. (2004). Smart Risk (1st ed.). Chichester: Capstone.

Hopkins, A. (2011). Management Walk-Arounds: Lessons from The Gulf of Mexico Oil Well Blowout. Safety Science 49(10), 1421-1425. https://doi.org/10.1016/j.ssci.2011.06.002

HSE. (2010). Major Hazards, HSE About HSE Strategies and plans Plans Archive Business Plan 04-05 Major hazards.

Huczynski, A. A., \& Buchanan, D. A. (1991). Organizational Behaviour, Prentice-Hall, Hemel Hempstead. International Journal of Mass Emergencies and Disasters, 16, 13-43.

Kalantarnia, M., Khan, F., \& Hawboldt, K. (2009). Dynamic risk assessment using failure assessment and Bayesian theory. J Loss Prev Process Ind, 22, 600-606. https://doi.org/10.1016/j.jlp.2009.04.006

Khan, F. J., Hashemi, S., Paltrinieri, N., Amyotte, P., Cozzani, V., \& Reniers, G. (2016). Dynamic risk management: A contemporary approach to process safety management. Current Opinion in Chemical Engineering, 14, 917. https://doi.org/10.1016/j.coche.2016.07.006

Kjellén, U. (2000). Prevention of Accidents through Experience Feedback. Taylor \& Francis, London.

LaPorte, T. R., \& Consolini, P. M. (1991). Working in practice but not in theory: theoretical challenges of highreliability organizations. Journal of Public Administration Research and Theory, 1(1), 19-47.

Lempert, R. J. (2002). A new decision sciences for complex systems. Proc. Natl. Acad. Sci., 99, 7309-13. https://doi.org/10.1073/pnas.082081699

Leveson, N. G. (2011). Engineering a Safer World: System Thinking Applied to Safety. Massachusetts Institute of Technology Press, Cambridge. https://doi.org/10.7551/mitpress/8179.001.0001

Linkov, I., Satterstrom, F., Kiker, G., Batchelor, C., Bridges, T., \& Ferguson, E. (2006). From comparative risk assessment to multi-criteria decision analysis and adaptive management: Recent developments and applications. Environ. Int., 32, 1072-93. https://doi.org/10.1016/j.envint.2006.06.013

Marek, J., Tangenes, B., \& Hellesouy, O. (1985). Experience of Risk and Safety. Work Environment Statf-jord Field. Oslo University.

Meshkati, N. (1995). Human Factors in Process Plants and Facility Design. In Cost-Effective Risk Assessment for Process Design (R. D. Deshotels and R. Zimmer-man, eds.), McGraw-Hill, New York, pp. 113-130.

Meshkati, N. (1999). Cultural Context of Nuclear Safety Culture: A Conceptual Model and Field Study. In J. Misumi, B. Wil-pert, \& R. Miller (Eds.), Nuclear Safety: A Human Factors Perspective (pp. 61-75). Taylor and Francis, London. https://doi.org/10.1201/9780203212073.ch4

Morone, J. G., \& Woodhouse, E. J. (1986). Averting Catastrophe: Strategies for Regulating Risky Technologies. University of California Press, Berkeley, CA.

National Commission on the BP Deepwater Horizon Oil Spill and Offshore Drilling, (2011). Deep Water the Gulf Oil Disaster and the Future of Offshore Drilling. Report to the President.

National Research Council, (U.S.). Macondo Well Deepwater Horizon Blowout: Lessons for Improving Offshore Drilling Safety. Washington, D.C.: National Academies Press, 2012. eBook Collection (EBSCOhost). Web. 14 Jan. 2017.

National Research Council. (2012). Macondo Well Deepwater Horizon Blowout: Lessons for Improving Offshore Drilling Safety. Washington, D.C.: National Academies Press, eBook Collection (EBSCOhost), EBSCOhost, 
viewed 29 December 2016.

Norsok (Standards Norway) (2004). Well Integrity in Drilling and Well Operations D-10 (3rd ed.). Oslo, Norway.

NRC. National Research Council of the United States National Academy of Sciences. Adaptive Management for Water Resources Project Planning. Washington, DC: The National Academies Press; 2004.

Oedewald, P., Pietikäinen, E., \& Reiman, T. (2011). A Guidebook for Evaluating Or-ganizations in the Nuclear Industry: An Example of Safety Culture Evaluation. Report No. 2011:20, Swedish Radiation Safety Authority. Retrieved Jan. 17, 2012, from http:/www.stralsaker rhetsmyndigheten.se/Global/Publikationer/Rapport/Sakerhet-vid-karnkraftverken/2011/SSM-Rapport-201120.pdf

Øien, K., Utne, I. B., Herrera, I. A. (2011a). Building safety indicators. Part 1 - Theoretical foundation. Safety Science. https://doi.org/10.1016/j.ssci.2010.05.012

Ornelas, D., Mendes, P., Magrini, A., \& Arouca, M. (2014). Offshore oil and gas exploration and production in Brazil: A proposal for integrated actions for operational, occupational and environmental safety. The Journal of World Energy Law \& Business, 7(4), 340-363. https://doi.org/10.1093/jwelb/jwu022

Park, J., Seager, T., \& Rao, P. (2011). Lessons in risk- versus resilience-based design and management. Integrated Environmental Assessment and Management, 7(3), 396-9. https://doi.org/10.1002/ieam.228

Rasmussen, J. (1997). Risk Management in a Dynamic Society: A Modeling Problem. Safety Science, 27(2/3), 183-213.

Rasmussen, J., \& Svedung, I. (2000). Proactive Risk Management in a Dynamic Society. Swedish Rescue Services Agency, Karlstad. Retrieved Jan. 17, 2012, from https:/www.msb.se/RibData/Filer/ pdf/16252.pdf

Roberts, K. H. (1990) Some characteristics of one type of high reliability organization. Organization Science, 1, 160-176. https://doi.org/10.1287/orsc.1.2.160

Rundmo, T. (1993). Risk perception and occupational accidents on offshore petroleum platforms. Paper presented at the 2nd Offshore Installation Management Conference, The Robert Gordon University, Aberdeen, April.

Shaughnessy, J. M., Romo, L. A., \& Soza, R. L. (2003). Problems of Ultra-Deep High-Temperature, High-Pressure Drilling, SPE Annual Technical Conference and Exhibition. Society of Petroleum Engineers, Denver, USA, October 5-8. https://doi.org/10.2118/84555-MS

Skogdalen, J. E., Ingrid, B. U., \& Jan, E. V. (2011). Developing Safety Indicators for Preventing Offshore Oil And Gas Deepwater Drilling Blowouts. Safety Science, 49, 8-9, 1187-1199. https://doi.org/10.1016/j.ssci.2011.03.012

Skogdalen, J., Khorsandi, J., \& Vinnem, J. (2012). Evacuation, escape, and rescue experiences from offshore accidents including the Deepwater Horizon. Journal of Loss Prevention in the Process Industries, 25(1), 148158. https://doi.org/10.1016/j.jlp.2011.08.005

Skogdalen, J., Utne, I., \& Vinnem, J. (2011). Developing safety indicators for preventing offshore oil and gas deepwater drilling blowouts. Safety Science, 49(8-9), 1187-1199. https://doi.org/10.1016/j.ssci.2011.03.012

Sylves, R. T. (1998). How the Exxon Valdez disaster changed America's oil spill management.

Sylves, R. T., \& Comfort, L. K. (2012). The Exxon Valdez And BP Deepwater Horizon Oil Spills: Reducing Risk in Socio-Technical Systems. American Behavioral Scientist, 56(1), 76-103. https://doi.org/10.1177/0002764211413116

Teece, D. (2009). Dynamic capabilities and strategic management. New York: Oxford University Press. https://doi.org/10.1142/9789812834478_0002

Teece, D., Peteraf, M., \& Leih, S. (2016). Dynamic Capabilities and Organizational Agility: Risk, Uncertainty, and Strategy in the Innovation Economy. California Management Review, 58(4), 13-35. https://doi.org/10.1525/cmr.2016.58.4.13

The Commonwealth Scientific and Industrial Research Organisation. (2013, June 6). The Commonwealth Scientific and Industrial Research Organisation. Retrieved July 19, 2013, from http://www.csiro.au/

The U.S. Nuclear Regulatory Commission Safety Culture Policy Statement (U.S. NRC 2011).

The United States Bureau of Safety and Environmental Enforcement-Safety Culture Policy Statement 2013.

USDI (US Department of the Interior), 2010. Increased Safety Measures for Energy Development on the Outer 
Continental Shelf.

Van Der Voort, H., \& De Bruijn, H. (2009). Learning from disasters. Technology and Society Magazine, IEEE, 28(3), 28-36. https://doi.org/10.1109/MTS.2009.934160

Weick, K. E. (1987). Organizational culture as a source of high reliability. California Management Review, 29 , 115-128. https://doi.org/10.2307/41165243

Woodhouse, E. J. (1988) Sophisticated trial and error in decision making about risk. In M. E. Kraft, \& N. J. Vig. (Eds.), Technology and Politics. Duke University Press, Durham, NC.

Xie, G., Yue, W., Wang, S., \& Lai, K. (2010). Dynamic risk management in petroleum project investment based on a variable precision rough set model. Technological Forecasting and Social Change,77(6), 891-901. https://doi.org/10.1016/j.techfore.2010.01.013

\section{Web References}

http://www.ifp-school.com/upload/docs/application/pdf/2015-02/7_blowout_preventer_stack.pdf

http://www.hse.gov.uk/aboutus/strategiesandplans/hscplans/businessplans/0405/07.htm (13.11.10).

http://www.slb.com/services/technical_challenges/deepwater_operations.aspx

\section{Copyrights}

Copyright for this article is retained by the author(s), with first publication rights granted to the journal.

This is an open-access article distributed under the terms and conditions of the Creative Commons Attribution license (http://creativecommons.org/licenses/by/4.0/). 